\title{
Investigation of Temperature Effects on Microstructure of Pure Titanium
}

\author{
E Aygul ${ }^{1 *}$, Y Sahin $^{2}$ and S Yalcinkaya ${ }^{1}$ \\ ${ }^{1}$ Department of Mechatronics Engineering, Marmara University, Turkey \\ ${ }^{2}$ Department of Mechanical Engineering, Near East University, Turkey
}

Submission: July 01, 2020; Published: July 21, 2020

*Corresponding author: E Aygul, Department of Mechatronics Engineering, Marmara University, Turkey

\begin{abstract}
In this study, pure titanium powders were sintered by sealing in quartz tubes vacuumed from oxygen for 4 hours at 3 different temperatures by using powder metallurgy method. Temperature values selected for sintering of samples are $900^{\circ} \mathrm{C}, 1000^{\circ} \mathrm{C}$ and $1150^{\circ} \mathrm{C}$ respectively. SEM, EDX, XRD tests were performed for microstructure analysis of samples produced by powder metallurgy, and finally, the effects of sintering temperature on the microstructure of pure titanium were determined by measuring the Vickers hardness values of the samples. According to the results obtained, the sintering temperature has great effects on the microstructure of pure titanium. In addition, the Vickers value measured for $900 \mathrm{CC}$ as $263 \mathrm{kgf} / \mathrm{mm} 2$, for $1000^{\circ} \mathrm{C}$ as $382 \mathrm{kgf} / \mathrm{mm}^{2}$ and finally $528 \mathrm{kgf} / \mathrm{m} \mathrm{m}^{2}$ for $1150^{\circ} \mathrm{C}$ temperature sintering.
\end{abstract}

Keywords: Pure-Ti; Sintering Temperatures; Microstructure; Powder Metallurgy

\section{Introduction}

Titanium is the most widely used implant of recent years, because of its protective effect on between bond and tissue during implantation, also triggering the formation of calcium ions around it and accelerating bone formation [1]. Titanium also experiences an allotropic $\alpha$-phase to $\beta$-phase transformation at a temperature of $882^{\circ} \mathrm{C}$, which causes the most important mechanical properties of the metal to be changed, particularly the flexibility. There is no guarantee that the metal undergoing allotropic transformation will remain in a continuous $\beta$-phase structure [2]. When the metal descends to room temperature, all of the weak $\beta$-phase structures can be transformed into $\alpha$-phase structures. This critical transformation can be vital for these metals used in human tissues and organs [3]. Also, the microstructure of titanium implants is known to have important effects on the most important parameters of the implant, such as corrosion. Even though titanium allotropic conversion begins at $882^{\circ} \mathrm{C}$, a stable microstructure at this temperature may not be possible. Therefore, it is very important to discover a temperature and homogeneous microstructure in titanium metal and a temperature value in which the elevated B phase region coexists. In this case, it has been found suitable for the same metal types to increase the small sintering temperature by starting the experiment at the temperature value where allotropic conversion starts. Therefore, in this study, starting from the allotropic transformation temperature value, three pure titanium were produced at $900^{\circ} \mathrm{C}, 1000^{\circ} \mathrm{C}$ and $1150^{\circ} \mathrm{C}$ temperatures respectively. Analyses of the samples were compared by XRD, SEM, Micro Hardness measurements. In order to produce pure titanium metals, powder metallurgy has been the chosen method for the production, considering its success in producing metals with high melting temperatures.

\section{Experimental Methods}

The powders of the metals used in this study were obtained from the Nanography company. Characteristic properties of these powders are Titanium (Ti) Purity: 99.9\%, Size: 100 mesh, density $4,507 \mathrm{~g} / \mathrm{cm}^{3}$. The metal powders pressed in an $11 \mathrm{~mm}$ diameter pellet die for 30 minutes at $20 \mathrm{Mpa}$ pressure. The pressed sample sintered in oxygen vacuumed environment. The sintering process was carried out at $900^{\circ} \mathrm{C}, 1000^{\circ} \mathrm{C}$ and $1150^{\circ} \mathrm{C}$ for 4 hours respectively. sintered sample is given in Figure 1.

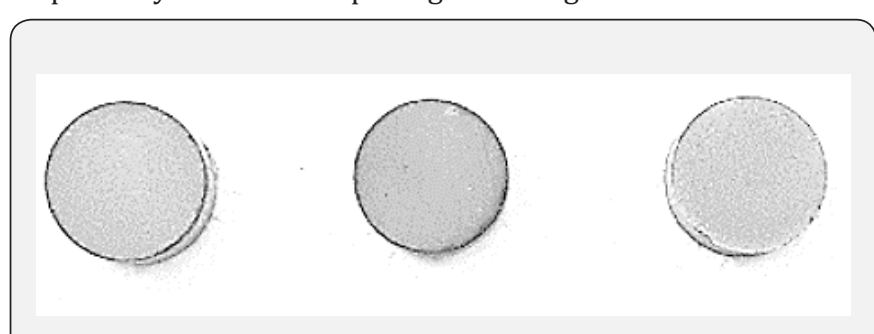

Figure 1: The produce Ti-samples by powder metallurgy. 
X-ray diffraction analysis (XRD) was performed for phase analysis of Pure Titanium and Cobalt alloys produced by powder metallurgy. Measurements were made using XRD-6100 Shimadzu, XRD scanning Range (100-900), Cu X-ray tube target, voltage = $40.0(\mathrm{kV})$ and current $=30.0(\mathrm{~mA})$ measurement details used. Scanning electron microscopy (SEM) was used to compare the sample (P/M) particle size, pore diameters, and oxide content. The surface morphology of the samples was observed using an area emission scanning electron microscope (FEI XL30 Sirion). Hardness measurements, (Micro Hardness Tester FM-310e) was used to obtain the hardness values of the surface of the samples. Hardness values were taken under $100 \mathrm{~g}$ load for $10 \mathrm{sec}$. Hardness values were taken from 5 different points on the surface of the sample. The average of 5 Vickers values was accepted as the final hardness value.

\section{Results and Discussion}

\section{SEM And EDX Analysis}

Figure 2 shows XRD pattern of pure titanium diffractometers sintered at $900^{\circ} \mathrm{C}, 1000^{\circ} \mathrm{C}, 1150^{\circ} \mathrm{C}$ respectively. Accordingly, targeted Titanium diffractometers were achieved at all 3 temperatures. The XRD cards of the titanium structures obtained were found to be $00,044,1294>$ Ti for all 3 samples. It is seen that $\alpha$-Ti (hcp) structures are transformed to $\beta$-Ti (bcc) structures with increasing sintering temperature. Finally, the final $\beta$-Ti phases are formed at $1150^{\circ} \mathrm{C}$.

Figure 1: The XRD spectra of Pure-Ti.

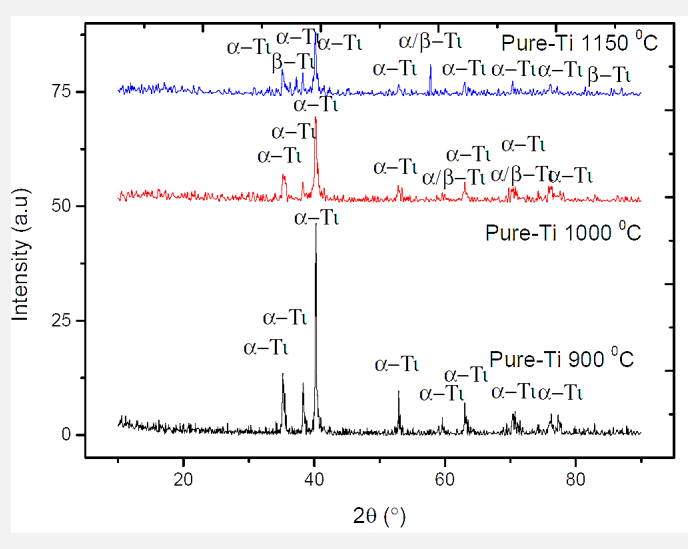

Figure 3 (f) An example is provided for EDX analysis of samples. As can be seen in the picture, there is a dominant Titanium peak, and there is no oxidation in samples. SEM images of pure titanium metals produced at three different temperature values $\left(900^{\circ} \mathrm{C}\right.$, $1000^{\circ} \mathrm{C}$ and $1150^{\circ} \mathrm{C}$ ) have a more stable surface morphology.
Furthermore, the pore structures seen in this sample appear to be more uniform and closer to spherical geometry. It is seen that pore diameters and grain size values decrease as sintering temperature increases.

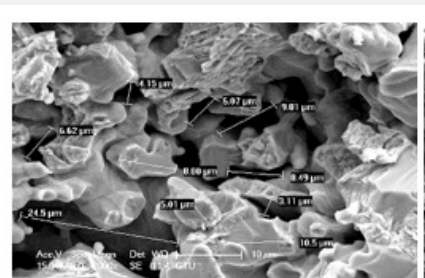

a

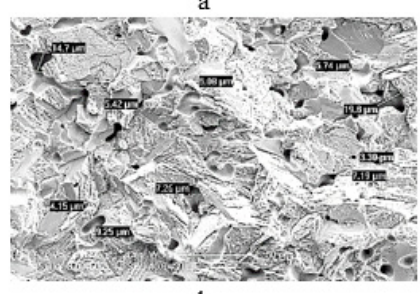

d

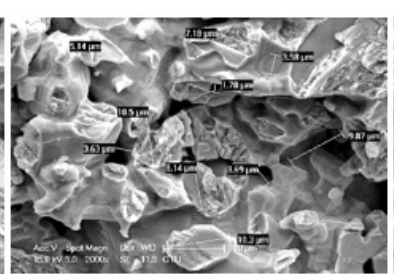

b

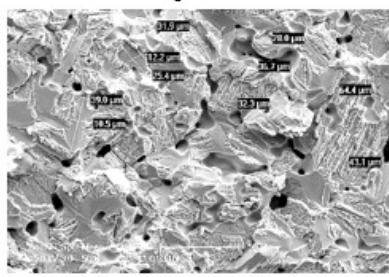

e

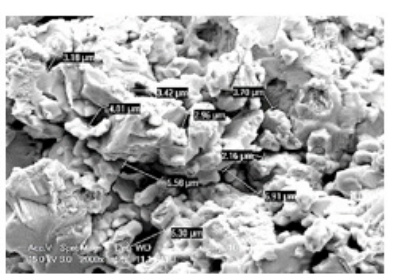

c

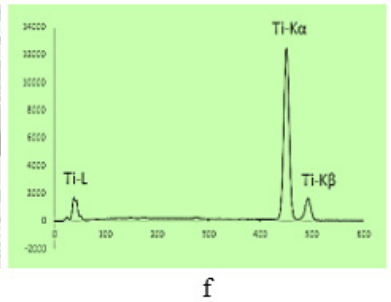

Figure 3: The SEM images of Pure-Ti (a,b-900oC), (c-1000oC), (d,e-1150oC) and (f-EDX spectrum of Pure-Ti). 


\section{Micro Hardness Tester}

The Vickers hardness tester is the test engine that least damages the sample among the material tests. Similar properties have been reported between the Vickers hardness and mechanical properties of a material. Hardness measurements, Vickers hardness Notch machine (Micro Hardness Tester FM-310e) was used to obtain the hardness values of the surface of the samples. The hardness values were taken under a load of $100 \mathrm{~g}$ for a 10 -sec holding time. Hardness values were taken from 5 different points on the surface of the sample. The average of 5 Vickers values was accepted as the final hardness value. The average hardness values were given at Table 1.

Table 1: The Vickers Hardness values of Pure-Ti.

\begin{tabular}{|c|c|c|c|}
\hline Micro Hardness Tester & $\mathrm{Ti}-900^{\circ} \mathrm{C} \mathrm{HV}\left(\mathrm{kgf} / \mathrm{mm}^{2}\right)$ & $\mathrm{Ti}-1000^{\circ} \mathrm{C} \mathrm{HV}\left(\mathrm{kgf} / \mathrm{m} \mathrm{m}^{2}\right)$ & $\mathrm{Ti}-1150^{\circ} \mathrm{C} \mathrm{HV}\left(\mathrm{kgf} / \mathrm{m} \mathrm{m}^{2}\right)$ \\
\hline \multirow{5}{*}{ Produce different temperature of pure-Ti } & 241 & 351 & 515 \\
\hline & 245 & 362 & 516 \\
\hline & 260 & 384 & 523 \\
\hline & 282 & 403 & 525 \\
\hline & 287 & 407 & 563 \\
\hline Average Value & 263 & 382 & 528 \\
\hline
\end{tabular}

\section{Conclusion}

Pure titanium powders are produced by powder metallurgy at different temperatures. As the sintering temperature increased, the $\beta$-phase region increased in the samples, particle sizes and pore diameters decreased and finally micro hardness values increased. Homogeneous microstructure was obtained in all three samples.

\section{References}

1. Geetha M, Durgalakshmi D, Asokamani R (2010) Biomedical implants: corrosion and its prevention-a review. Recent patents on corrosion science.

2. Omar O (2020) Cellular and molecular reactions to dental implants. Dental Implants and Bone Grafts. Woodhead Publishing pp. 183-205.

3. Stepanovska J, Matejka R, Rosina J, Bacakova L, Kolarova H (2020) Treatments for enhancing the biocompatibility of titanium implants. A review 164(1):23-33.

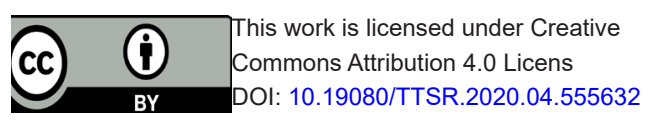

